\title{
Gold of California
}

\section{C.S. Lyman}

To cite this article: C.S. Lyman (1850) Gold of California, Philosophical Magazine Series 3 , 36:242, 243-243, DOI: $10.1080 / 14786445008646466$

To link to this article: http://dx.doi.org/10.1080/14786445008646466

曲 Published online: 30 Apr 2009.

Submit your article to this journal

LII Article views: 1

Q View related articles $₫$ 
Messrs. Bowman and Ebbett of New York state that much gold appears to be disseminated throughout the gangue, in so minute a state of division as to be invisible to the naked eye.-Proc. Amer. Phil. Soc. 1849, p. 85.

\section{GOLD OF CALIFORNIA. BY C. S. LYMAN.}

The gold the past season has turned out much better than was expected. Many rich deposits in all parts of the mines have been opened. On the middle fork of the Rio de los Americanos, two men

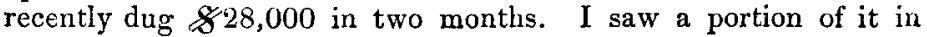
lumps of the size of hen's eggs, and larger. The Mariposa has yielded several similar prizes, and so has the Mokelemnes. But for these few fortunate diggers, there are thousands who scarce earn a dollar a day. From the best information I can get, industrious workers have not averaged more than eight or ten dollars a day-some estimate it much lower ; multitudes do not pay expenses, particularly clerks, professional men, and others unaccustomed to hard work.

The gold has at last been discovered in place-in veins penetrating quartz beds-on the Mokelemnes, and in the vicinity of the Mariposa and one or two other places. I have this from gentlemen who have seen the veins, and who are reliable witnesses. These veins are of course not worked yet, as it is more profitable to dig the wash gold. One of these veins has been "denounced" (as it is termed) under the Mexican laws, by Mr. Fremont. The working of the innumerable rich veins, which undoubtedly will be opened in the mountains, will constitute an immense and profitable mining business for centuries. I have no fear that the gold, as many imagine, will all be dug out in a year or two.--Silliman's Journal, January 1850 .

\section{ON THE OIL OF ELEMI. BY M. H. DEVILLE.}

The author states that $M$. de Bonastre subjected the resin of elemi to distillation with water and obtained an oily principle, respecting which he merely stated that it had been produced.

Some time since Mr. Stenhouse published a series of experiments on the oils of olibanum and elemi.

There are several varieties of elemi which differ from each other in consistence and the quantity of ligneous matter accidentally and intimately intermixed. 'This resin is sometimes as sof as thick honey, and at other times solid and hard, according to the degree of alteration which it has undergone by exposure to the air. It will therefore be readily conceived that the quantities of oil of elemi produced by distilling the resin may vary, as proved by the numbers of Mr. Stenhouse, M. De Bonastre and the author's, very considerably. Some specimens of elemi of good quality yicided $M$. Deville more than 13 per cent. of oil.

After the usual purifications, which are very readily effected, the 